\title{
Homecare user needs from the perspective of the patient and carers: a review
}

This article was published in the following Dove Press journal:

Smart Homecare Technology and TeleHealth

29 July 2014

Number of times this article has been viewed

\section{Debbie Isobel Keeling}

School of Business and Economics, Loughborough University,

Loughborough, UK
Correspondence: Debbie Isobel Keeling School of Business and Economics, Epinal Way, Loughborough University, Loughborough, Leicestershire LEII 3TU, UK Tel +44 I509 223 II7

Email d.i.keeling@lboro.ac.uk

\begin{abstract}
There is a global shift towards a blending of care delivery within formal and informal environments in direct response to economic and demographic pressures. Homecare is at the hub of this activity, enabling people to age in place and keeping families intact. However, our understanding of patient and carer needs is fragmented; understandably so, given the complexity of these needs. This descriptive review offers a content analysis of papers focused on patients' and carers' needs and homecare published between January 2010 and October 2013. It is evident that homecare is an intensely researched area, yet it is disjointed. Emerging research emphasizes the need to take a holistic approach. Firstly, incorporating emotional psychosocial and cultural elements will help to draw together our current understanding within a more cohesive framework. Secondly, tensions that hinder communication and collaboration between stakeholders must be resolved. Thirdly, information and communications technology is rapidly becoming synonymous with homecare, and offers solutions for facilitating care delivery, collaboration, and training of future professionals. The rate of international activity promises much for future research collaborations to compare, contrast, and identify best practices for the future of homecare as we endeavor to meet the ever-increasing pressures on health and social care systems.
\end{abstract}

Keywords: homecare, home health care, patient needs, caregiver needs, telehealth, telemonitoring, patient-centered care

\section{Introduction}

Within Western societies, there has been a shift from the delivery of health care in formal settings to a blending of health care delivery within both formal and informal settings. ${ }^{1-4}$ To cope with the increasingly aging population, demands for hospital beds outstripping supply, and cuts in funding for hospital services, homecare is viewed as a viable solution to help reduce costs while maintaining quality of care. ${ }^{2}$ The relative advantage of homecare in comparison to hospital care may not be clear-cut, relying heavily on the specific context and focused "capacity building" of the service. ${ }^{3}$ However, advancements in technology and treatments support homecare as a feasible and effective option, raising the potential complexity of care provision possible at home to levels comparable with hospital care. ${ }^{5}$ Most importantly, homecare is often the preferred option for many patients, their families, and carers, regardless of condition, ${ }^{6,7}$ though the physical, monetary, and emotional costs of providing care at home can be a burden to patients and their families eventually. ${ }^{3}$

Homecare studies have tended to focus on one aspect of homecare - recipient characteristics and the organization of homecare - as revealed in a recent comprehensive review of homecare across Europe (January 1998 to October 2009). ${ }^{6}$ To harness 
current knowledge more effectively and bring about better patient outcomes, a uniform framework and methodology for researching homecare are needed. A vital ingredient is that this framework be focused around an understanding of the patients' needs for homecare. ${ }^{6,8}$ Therefore, the focus of this review is to establish how studies focus on the needs of patients and their carers in homecare. Three key questions are posed:

1. What does homecare mean to patients and their carers, and how does this help us to understand their needs?

2. What is the scope of studies to date that focus on the homecare needs of (a) patients, (b) carers, and (c) patients and caregivers together?

3. What is the scope of studies of homecare technology in relation to patient and carer needs?

Following a brief description of the review methodology, the paper is structured around answering these three questions. The scope of studies is evaluated through identifying the main themes within each category and summarizing the issues covered. As such, readers are provided with a comprehensive summary of the coverage of patient and carer needs in extant research. In conclusion, a framework for understanding patient and carer needs is offered alongside three recommendations for future research.

\section{Review methodology}

As set out in the research questions, the goal of the review is to capture the scope of research to date, rather than offering a meta-analysis. A focused search was conducted using Medline of homecare studies conducted from January 2010 until October 2013. Entering the search terms "homecare" or "home health" and "needs" returned 714 papers. Each paper was visually inspected, and papers were excluded on the basis of being historical reviews; political statements; commentaries; events-based posters; finance- and insurancerelated studies; legal studies; nursing home or hospice studies; evaluations of specific treatments where homecare was the context, not the focus; "homecare" of teeth that was not related to delivery of homecare to patients; pregnancyand children-related studies; policy, system, and management overviews; mental health patient studies; occupational studies; and propositional papers. The vital criterion in selection was to identify those papers that studied patients' or carers' needs within homecare. This resulted in 182 papers being selected for further analysis. Ten of these studies related to the meaning of homecare needs. The remaining studies focused on patient needs (83), carer needs (29), patient and caregiver needs (32), and telehealth and device use (28).
A content analysis identifying the emerging themes within each category and the number of studies within each theme is presented. The main issues arising within each of those themes are summarized.

\section{What does homecare mean to patients and their carers, and how does this help us to understand their needs?}

What we understand by the term "homecare" is surprisingly varied. ${ }^{1}$ However, homecare definitions are understandably dominated by a professional or policy perspective, where homecare is defined at an operational level, ie, the formal delivery of care at home by health care professionals or accredited homecare agencies, such as nursing care or physical therapy. However, operational concepts of "formal" homecare vary in terms of the extent of what constitutes homecare, and are based on (and limited by) the political and funding structures that support these services, eg, the nature of domiciliary care to be provided. A further complication in defining homecare is that it demands an integration of both social and health care services to bring about successful care outcomes. However, the diversity in funding and organizational infrastructures for the delivery of health and social care services within many countries has promoted a fragmentation of these services. ${ }^{9}$

In contrast, patient-led (or carer) definitions of care often do not focus on a specific description of the "operational" care provided, but on wider aspects of life, such as emotional needs, quality of life (QoL), and empowerment. This means that the potential heterogeneity of care needs is vast. ${ }^{10}$ The extent of perceived needs is influenced by patient appraisals of disorders, especially the "controllability" or "surmountability" of the illness, and by their associated perceived and actual coping resources. ${ }^{11}$ Illness is "destabilizing" for patients and their carers, impacting on control, dignity, and decision-making abilities, and it is often these elements that drive a patient's concept of what constitutes care needs. ${ }^{1,12}$ Care from the patient's perspective often centers on a sense of "being looked after". ${ }^{12}$ This encompasses: 1) perceived convenience, accessibility, availability, and promptness of resources or services; 2) information about the condition, treatments, and alternatives; 3 ) interactions with caregivers (eg, sensitivity, empathy, friendliness, and respect); and 4) the physical comfort or otherwise of received care. An initial categorization of the diverse and complex patient and carer homecare needs is presented in Table 1. 
Table I Patient and carer need categories related to condition or illness

\begin{tabular}{|c|c|c|}
\hline Need category & Patient-related & Caregiver-related \\
\hline Treatment-related & $\begin{array}{l}\text { Medication (including adherence to regimen) } \\
\text { Nursing care } \\
\text { Prescribed treatments and procedures } \\
\text { Dietary instructions } \\
\text { Urination and bowel problems } \\
\text { Physical therapy } \\
\text { Individualization of care }\end{array}$ & $\begin{array}{l}\text { Management of care needs } \\
\text { Physical labor }\end{array}$ \\
\hline $\begin{array}{l}\text { Activities of daily } \\
\text { living (ADL) }\end{array}$ & $\begin{array}{l}\text { Personal care (bathing, toileting, dressing, } \\
\text { transferring, eating) } \\
\text { Instrumental ADL (shopping, light housework, meal } \\
\text { preparation, money management, telephone access) } \\
\text { Mobility (climbing stairs, getting outside the home, } \\
\text { ability to walk) } \\
\text { Fulfilling role commitments (care of others, } \\
\text { work-related) }\end{array}$ & $\begin{array}{l}\text { Physical burdens } \\
\text { Restrictions on autonomy/independence } \\
\text { Restrictions on leisure time } \\
\text { Spillover to other areas of life }\end{array}$ \\
\hline $\begin{array}{l}\text { Self-sufficiency } \\
\text { needs }\end{array}$ & $\begin{array}{l}\text { Transportation } \\
\text { Housing } \\
\text { Legal } \\
\text { Finance } \\
\text { Work }\end{array}$ & $\begin{array}{l}\text { Increased responsibility } \\
\text { Financial needs or burdens } \\
\text { Transportation needs or burdens }\end{array}$ \\
\hline Social needs & $\begin{array}{l}\text { Interpersonal interactions } \\
\text { Social support (from those sharing the same } \\
\text { home or from the wider network) } \\
\text { Open discussion } \\
\text { Avoiding dependency or "institutionalization in } \\
\text { the home" }\end{array}$ & $\begin{array}{l}\text { Help to adapt to disorder or death } \\
\text { Strengthening of family ties } \\
\text { Pressure on family and friend networks } \\
\text { Open discussion } \\
\text { Social reintegration (especially outside the inner network) } \\
\text { Not encouraging dependency (not "killing with } \\
\text { kindness") }\end{array}$ \\
\hline Emotional needs & $\begin{array}{l}\text { Role change (eg, from parent to “child”) or } \\
\text { identity (self-concept) needs } \\
\text { Loss of independence } \\
\text { Coping with physical restrictions (anger and } \\
\text { depression) } \\
\text { Fears of being alone } \\
\text { Guilt } \\
\text { Coping with added responsibility } \\
\text { Respite } \\
\text { Indebtedness } \\
\text { Demoralization }\end{array}$ & $\begin{array}{l}\text { Role change (eg, from child to "parent"), impact on } \\
\text { marriage or partnerships (eg, loss of spouse) } \\
\text { Burnout } \\
\text { Distress } \\
\text { Felt responsibility } \\
\text { Emotional labor } \\
\text { Nonreciprocity in nature of exchange relationship } \\
\text { (being "taken for granted") } \\
\text { Guilt } \\
\text { Respite } \\
\text { Self-esteem } \\
\text { Desensitization to condition } \\
\text { Demoralization } \\
\text { Inadequacy }\end{array}$ \\
\hline $\begin{array}{l}\text { Informational } \\
\text { needs }\end{array}$ & $\begin{array}{l}\text { Treatment uncertainty } \\
\text { Outcome uncertainty (eg, longevity, changing needs, } \\
\text { "realistic" expectations, "healthy" appraisals of } \\
\text { condition) } \\
\text { Condition myths }\end{array}$ & $\begin{array}{l}\text { Treatment uncertainty } \\
\text { Outcome uncertainty (eg, changing needs) } \\
\text { Condition myths (eg, fears of contagious nature of } \\
\text { disease) } \\
\text { Appropriate care provision }\end{array}$ \\
\hline
\end{tabular}

The changing nature of needs necessitates ongoing management with constant appraisal of the needs-care match. However, "home" in a service-delivery context is complex. The great variety in homes means that there is no level of standardization, making it difficult to develop protocols for service delivery or to guarantee that all services can be delivered. ${ }^{2,13}$ From the patient's point of view, their home is linked to their personal identity, and is a sign of independence, status, and family tradition, which offers security and privacy. ${ }^{2,14}$ Home is an important "therapeutic landscape" for the individual. The sense of attachment, continuity, and normalcy associated with homecare encourages feelings of well-being and enhances the efficacy of homecare by offsetting destabilizing effects of illness. ${ }^{2,15}$ The home is often the preferred choice of place to die, as it is easier to manage the taboo associated with death, dying, and serious illness, ${ }^{16}$ although the patient 
must perceive this care as appropriate, otherwise its value is reduced or even detrimental. ${ }^{15}$ The home as the context of care results in a complex interweaving of interactions between formal and informal carers and patients that are different from formal service settings. ${ }^{15}$

Notwithstanding, there is general agreement between patients, professionals, and carers that the goal of homecare is to enable an individual to remain in their home safely while receiving the services necessary to care for their conditionrelated needs, either following hospitalization or to prevent admissions and to facilitate aging in place. Put simply:

"Homecare is the total of services of healthcare that a patient can receive in his house, [. . . provision of nursing care of high quality under medical follow-up and at the same time the provision of social and psychological support of the patient and his family." ${ }^{17}$

While this poses challenges for homecare researchers in terms of the diversity of needs that could be studied, making a uniform framework difficult to develop, it does emphasize the importance of incorporating a holistic perspective on homecare into our studies.

\section{What is the scope of studies to date that have focused on the homecare needs of patients?}

As a means of understanding what a holistic perspective might encompass, a content analysis of the 83 studies focusing on patient needs was undertaken. Studies addressed a diverse range of patient needs, from issues related to access through to needs associated with specific conditions. The emerging themes are presented here, and the key issues raised under each theme are summarized.

\section{Access to care (six studies)}

Homecare can widen and promote equality in access to care. ${ }^{18}$ The reality of receiving treatment is that it places temporal, financial, and transportation burdens on the patient and/or carer, and for younger patients the need to arrange time off work. ${ }^{7}$ Homecare relieves these burdens for those living in rural and remote areas or those in vulnerable groups, such as poorer communities, the elderly, those with lower education, and those with reduced functional abilities. ${ }^{7,18-20}$ Those living in urban areas were more likely to live alone and have less access to informal caregiving (51.2\% in urban areas versus $82.8 \%$ in rural areas). ${ }^{19}$ However, those in rural communities may be forced to rely on informal care because of lack of access to formal services. ${ }^{21}$ Municipal characteristics impact on the amount and type of care an elderly person receives, even when they share similar care needs and personal characteristics. ${ }^{22}$

\section{Need profiles (six studies)}

Many of the studies reviewed focused on one or two specific aspects of homecare needs. ${ }^{6}$ Three studies focused on a wider profile of needs, confirming the complex mix of needs that patients (and their carers) have, ranging from medical and physical to the psychosocial. ${ }^{23-25}$ These studies identified malnutrition $(57 \%)$, weakness $(41.3 \%)$, and functional impairments $(40 \%)$ as the most prevalent needs across a variety of disorders. A comparative study identified heart failure patients as having an overall more complex need profile than other conditions. ${ }^{26}$ Two population studies estimated that the need for homecare in cancer patients may be as high as $69 \%-75.4 \% .^{27,28}$ Robison et al draw attention to unmet psychosocial needs, which must not be overlooked. ${ }^{25}$

\section{Unmet needs (I 5 studies)}

Studies estimate that between $23 \%$ and $50 \%$ of homecare patients have unmet needs. ${ }^{29,30}$ Unmet needs cover all areas, including activities of daily living (especially fall management), mental health, accompanying acute health problems, family caregiver burden, transportation, housing, and general practitioner lack of knowledge..$^{25,29-31}$ Concerns are raised about the resultant impact, such as increased nursing home admissions (eg, patients are 1.8 more times likely to be admitted when they have unmet needs). ${ }^{29}$ A lack of recognition of self-harm ideation and untreated depression leads to increased morbidity and mortality, increased nursing home institutionalization, and increased caregiver distress. ${ }^{32,33}$ Critics highlight that many avoidable risks are not given high priority, eg, fall prevention, oral care, and foot care ${ }^{34-38}$ Homecare programs can create unintended harm for patients, eg, mismanagement of nutrition, pressure ulcers, and medication regimens. ${ }^{39-41}$ Elder abuse recognition rates were low among professionals, suggesting mandatory abuse training for professionals and strategies to support reporters of suspected abuse. ${ }^{42}$

\section{Treatment-related needs (eleven studies)}

Studies concerned with treatment-related needs focused on malnutrition and anorexia (five), medication (four), pressureulcer prevention (three, two of which linked malnutrition with pressure-ulcer incidence), and pain management (two). The risk of malnutrition was viewed as a significant need. ${ }^{39,43,44}$ Incidence rates were similar across the two studies that quoted these, estimating malnutrition at $12 \%$ and $14 \%$ and high risk of malnutrition at $46 \%$ and $57 \% .{ }^{23,43}$ The incidence 
of anorexia was $25 \% .{ }^{45}$ Those with higher dependency (eg, lower functional ability) or in specific disease categories (eg, cancer) may be at a higher risk of malnutrition. ${ }^{23,43,44}$ Crucially, anorexia was linked to higher rates of mortality. ${ }^{45}$ Malnutrition was closely linked with the development of pressure sores..$^{39,43,46}$ The estimated incidence of pressure ulcers in a homecare population was estimated at $14.3 \%{ }^{46}$ Close supervision by the primary caregiver and education are primary factors in reducing pressure ulcers. ${ }^{39,46}$

Patients with complex medication regimens require support to avoid hospitalization. ${ }^{40}$ The incidence of medication-related problems in the homecare population may be around $4.6 \% .{ }^{47}$ However, this figure may be considerably higher for patients with eight or more medications - around $61 \%{ }^{48}$ Problems are linked to medications not suitable for deblistering into weekly dispensing systems, being interrupted when preparing medications at home, changes in medications not being communicated, suboptimal therapy, and use of unnecessary drugs. ${ }^{40,47}$ Of the three studies focusing on pain management, two established the safety and efficacy of patient-controlled analgesia in the homecare setting. ${ }^{49,50}$ The other study estimated that $1.4 \%$ of homecare patients in significant pain may have thoughts of suicide, with pain being linked to self-injury ideation in men. ${ }^{33}$

\section{Activities of daily living (eleven studies)}

The studies focusing on incidence of adverse events (two) reported remarkably similar rates of $13 \%$ per 100 patients and $13.2 \%$ across a mix of conditions. ${ }^{41,51}$ The two largest categories of adverse events are those related to medication (described earlier) and to falls. It was estimated that over $50 \%$ of these adverse events could be preventable. ${ }^{41}$ Reported falls incidence ranged from $55.7 \%$ to $70.6 \%$ of patients having at least one fall, $27.5 \%-44.2 \%$ of patients having recurrent falls across a mix of disorders. ${ }^{34,52}$ Falls were linked to malnourishment, specific disorders (cardiovascular diseases, hypertension, diabetes mellitus), pain, reduced vision, reduced cognitive ability, and environmental hazards. ${ }^{34,35,53}$ Emphasizing the lack of control over the home environment, one study revealed that $91 \%$ of homes have hazards related to falling, a rate of 3.3 per patient, with each hazard increasing the risk of a fall by $19 \% .^{53}$ As the risk of falling changes over time for each patient, it is difficult to assess for individuals. ${ }^{53}$

In relation to personal care, oral health and foot problems were neglected areas of homecare needs. ${ }^{36,37}$ The status of oral health was linked with nutrition through its impact on denture wearing and swallowing function, those with natural teeth having the fewest problems. ${ }^{38}$ Patients suffered from multiple foot problems, including edema, and thickened and discolored toenails, yet found it difficult to look after their own feet. ${ }^{37}$ In relation to functional ability, in a population study including Europe and Canada, there were wide differences in incidences of visual decline, ranging from $6 \%$ to $49 \% .{ }^{54}$ Visual decline is associated with reduced social contact, especially in outdoor activities. ${ }^{54}$ Homecare patients are in general weaker than normal for their age and sex, with $85.4 \%$ experiencing weakness in hand grip on one side or other. ${ }^{55}$

\section{Social and emotional needs (eleven studies)}

Depression, anxiety, and associated insomnia were significant problems for patients in homecare. ${ }^{56-58}$ Emotional dysfunction is the least well-identified and least well-treated need in homecare patients. ${ }^{25,56}$ One study estimated that $12 \%$ of patients in homecare suffer from depression, yet less than half of these receive appropriate treatment. ${ }^{57}$ Those that do receive treatment for one of these conditions may suffer side effects from long-term use of drugs. ${ }^{58}$ The importance of contact with the caregiver as a means of meeting comfort needs, the need to be connected, and alleviating loneliness cannot be underestimated in these cases. ${ }^{59,60}$ Homecare patients have the need to feel safe in their homes, receive empathy, and receive encouragement for participation in their health care. ${ }^{61,62}$ Those patients with end-of-life needs may have very specific wishes, eg, the wish to die at home or spiritual needs, yet they need to feel that their wishes are being listened to. ${ }^{63,64}$ There is a need for space for open discussion about "taboo" subjects, such as dying, but also communication with others that allows them to involve those around them in their "journey" and to take responsibility for the future. ${ }^{65}$

\section{Informational needs (two studies)}

Four key informational need areas were identified as important and neglected: 1) medication, specifically regimens, 2) disease or condition, specifically severity, 3) nonmedication, specifically hospital-discharge processes, wound care, medical equipment use, home safety, and extent of care, and 4) functional limitations. ${ }^{66}$ Communication problems were identified, in particular the need for continuous and updated information during treatment and care regarding prognosis and longevity of care. ${ }^{61}$

\section{Empowerment, quality of life, and homecare programs (26 studies)}

Homecare is a route to empowering patients. ${ }^{61}$ It can increase the acceptability of treatment and enable the choice to stay 
at home. ${ }^{7}$ For example, in one study, homecare enabled fulfillment of $98 \%$ of patients' choice of place of death. ${ }^{67}$ Participation in care is more achievable than in a hospital setting; patients are able to cocreate their care with homecare workers and have a choice over who works in their home. ${ }^{62}$ Many patients seek to "get on with life", constituting performance of daily activities, managing health, integrating life, and getting out/participating in life, with the best QoL that they can have. ${ }^{13,68}$ Homecare facilitates QoL by enabling people to stay in contact with their lives and families., ${ }^{7,69}$ Homecare programs can increase QoL, yet homecare can often be disrupted by funding shortages. ${ }^{68,70}$

Adopting such approaches as patient-centered homecare that focuses on the emotional and psychosocial aspects of disease, health-promotion activities, and restorative homecare programs facilitates QoL by increasing independence and empowerment. ${ }^{67,71-80}$ One study compared the Aging in Place (AIP) program with nursing care in the home, and found AIP to be an efficient and less costly service. ${ }^{81}$ While depression and anxiety linked with physical symptoms, especially pain, impact on QoL, these can be alleviated through appropriate emotional support, such as someone who will empathetically listen to anxieties and experiences. ${ }^{82,83}$ Through "accommodation", care provision can be responsive to the "singularity" of older adults to truly support independent living. ${ }^{84}$ Delivery of therapies within the homecare setting can alleviate impacts on QoL traditionally associated with hospital settings. For example, an intensive chemotherapy regimen at home was found to be feasible, effective, and not to reduce QoL for the patient. ${ }^{85}$

\section{Patient satisfaction ( 12 studies)}

Patient satisfaction with homecare is considered an essential means of benchmarking, identifying best practice, and delivering quality care ${ }^{86}$ Homecare can improve patient satisfaction with health care. ${ }^{5,87}$ Assistive devices in homecare settings are most often associated with increased satisfaction with care. ${ }^{88-90}$ However, a lack of consensus over the constituents of satisfaction and its measurement have hindered its use in the monitoring of homecare. ${ }^{86,90}$ Patient satisfaction can be summarized in four key dimensions: availability, accessibility (nondiscriminatory, physical accessibility, affordability, information accessibility), acceptability (eg, adequate conditions at home, not being afraid to use assistive devices or follow medication regimens), and quality. ${ }^{91-96}$ Some have emphasized the advantages of a qualitative approach to "connect the voice" of patients, caregivers, and professionals, although the level of commitment required for such an approach is huge. ${ }^{92}$

\section{Reducing hospitalizations, mortality, and costs (eleven studies)}

Homecare reduces hospitalization, readmission rates, use of emergency services, and associated costs. ${ }^{5,67,69}$ For example, a US-based comparative trial of the AIP program versus nursing homecare showed reduced costs of $\$ 1,591.61$ per month in the AIP group. ${ }^{81}$ Homecare reduces avoidable hospitalizations in particular, especially in remote areas. ${ }^{20}$ Reasons for this include patients not being exposed to nosocomial risks, higher "attendance" rates than clinics, and alleviating the risks of seeking care too late. ${ }^{7,19,69}$ There is evidence of reduced mortality risk in those patients receiving homecare, especially in vulnerable groups. ${ }^{97,98}$ Cost savings are found through the optimization of specialist nursing time. ${ }^{7}$ However, homecare needs to be targeted at the right patient population; it is not a blanket remedy. Costs are uniformly reduced in homecare settings, and the use of homecare and costs increase each week before death. ${ }^{99,100}$

\section{What is the scope of studies to date that have focused on the homecare needs of carers?}

Of these studies, 18 focused on formal (paid) caregivers, and only eleven on informal caregivers. As earlier, the emerging themes are presented, and the key issues raised under each theme are summarized. With regard to the informal caregiver category first, these studies overwhelmingly focused on their emotional or social needs. Only one study focused on the information needs related to the care of hemodialysis patients. ${ }^{101}$

\section{Emotional and social needs of informal caregivers (ten studies)}

The Family Difficulty Scale identifies eight categories of concerns: burden of care, concerns about homecare doctor, balance of work and care, patient's pain and condition, concerns about visiting nurse, concerns about homecare service, relationship between family caregivers and their families, and funeral preparations. ${ }^{102}$ One study found $22 \%$ of informal caregivers could be formally classified as distressed. ${ }^{103}$ Distress was a function of the interaction between the severity of the patient's condition and functionality, and the degree of the carer's positive outlook and personal resources. ${ }^{103,104}$ Uncertainty with regard to outlook and continuity of financial burdens exacerbated caregiver distress. ${ }^{105}$ The burden related to ongoing surveillance in terms of provision of care, prevention of injuries, and home safety was noted. ${ }^{106}$ 
The relationship between family caregivers and formal home-health professionals is important, especially in situations where the patient is unaware of the severity of their condition. ${ }^{107-110}$ The focus of this relationship is often on a negotiation of caregiving, helplessness, and interventions. ${ }^{108}$ A good caregiver-nurse relationship results in practical benefits, such as assisting in assessment of needs and improving access to necessary care, ${ }^{110}$ whereas a poor relationship leaves caregivers with feelings of powerlessness and "being left out"; they have a need to be "visible" in the care process. ${ }^{109}$ Caregiver and nurse perspectives could be misaligned, as caregivers are focused on the particular care of a single patient, whereas nurses are focused on shaping different realities within different homes. ${ }^{107}$

Two studies focused on the social norms or pressures to take on the role of caregiving. Caregivers often take on the responsibility of caring as a "natural" role. ${ }^{109}$ However, it was noted that female caregivers may take on the role of caregiver to a spouse because of the "gendered standards" with regard to caregiving roles in society. In such cases, other duties or roles may be neglected and women's choices reduced. ${ }^{111}$

\section{Formal caregivers (I8 studies)} Job strain and changing environment (seven studies) While occupational studies are not within the scope of this review, seven studies that focused on the overall strain of the job are pertinent here. Four studies highlighted the responsibility, safety, and physical demands of the role, in accordance with Table $1 .^{31,62,112,113}$ These studies highlighted training gaps and the need for direction from supervision and appropriate documentation and guidelines. ${ }^{31,62}$ The other three studies focused on the fast-changing environment and its impact on formal caregiving. Fragmentation of care, characterized by increasing time pressures, pressures on care resources, and increased demand, was experienced by care workers as "being on the verge", ${ }^{114-116} \mathrm{ie}$, increasingly feeling that they are being pushed to the limits of their capabilities and increasingly working against their professional standards, with concerns for the delivery of quality care.

\section{Treatment-related (five studies)}

It was estimated that $80 \%$ of formal caregivers provided nursing care in the home (50\% moderate-to-complex tasks), which was experienced as significantly more straining than the provision of personal care. ${ }^{117}$ Four studies focused on exposure risk (blood and body fluids). Top risks were from dressings (31.1\%), capillary blood glucose monitoring $(14.4 \%)$, and vascular access $(3.1 \%)$, deemed to be at a risk level comparable to the hospital environment. ${ }^{118}$ In one study, $6.3 \%$ of homecare workers reported an incident of exposure to blood or body fluids. ${ }^{119}$ Only $86 \%$ of homecare workers in one study reported always being provided with the correct protective equipment; adverse working conditions impacted on its use. ${ }^{120}$ Lack of an infection-control management plan and increased risk in smaller homecare agencies was noted. ${ }^{121}$

\section{Emotional and social needs (six studies)}

The role of the professional caregiver is multifaceted, incorporating acceptance, listening, support, and direction within a genuine caring dimension. ${ }^{122,123}$ Within the sociocultural context of care, homecare workers face contradictions or tensions concerning these elements. They need to connect with the patient and/or families and be able to withdraw, they need to enable patients and families, and at the same time administer care or make decisions that are disabling. ${ }^{14,124}$ They need to be able to visualize and communicate with patients and families about what is to come and what can be done. ${ }^{125}$ In terms of decision making, they need to take account of family caregivers, the patient, and the context of care. ${ }^{110}$

\section{Informational needs (one study)}

One study evaluated homecare workers' knowledge of evidence-based education topics in managing heart failure. ${ }^{126}$ While there was a $78.9 \%$ knowledge level in heartfailure education principles, some areas were weak. These included knowledge related to asymptomatic hypotension ( $24.5 \%$ correct), daily weight monitoring ( $26.6 \%$ correct), and transient dizziness $(30.9 \%$ correct).

\section{What is the scope of studies focusing on combined patient and caregiver needs?}

Thirty-two studies focused on the interrelationships between patient, family, and professionals. When the home becomes a place of care, the meaning of this formerly private area is changed, and the meaning of professional care is also changed. ${ }^{127}$ Homecare, as a cocreating activity recognizing the authority and influence of the person in their own home, can be delivered through "friendships" rather than "power relations". ${ }^{127}$ Cocreation is a prerequisite for the negotiation of intimate care. ${ }^{15}$ The cooperation of the entire family in care is associated with greater family health. ${ }^{10}$ When an informal caregiver is present, nonadherence is reduced; conversely, caregiver strain is associated with increased nonadherence. ${ }^{26}$ Caregiver confidence about the patient's ability 
to recover leads to improvements in activities of daily living; when both parties are confident, even greater improvements are observed. ${ }^{128,129}$

Stakeholder communication and collaboration were major concerns. ${ }^{5,66,130}$ Homecare relies on information sharing across multiple stakeholders, yet there is a lack of consensus on how this should be done. ${ }^{131}$ Transparent and flexible communication and collaboration between patients and their families and professionals is required. ${ }^{132-134}$ Interventions to improve communication and collaboration include professional training, partnerships with pharmacists, and community activities. ${ }^{135,136}$ New care models foster successful collaborations, eg, specialist schemes for palliative care at home and the implementation of shared decision making in homecare. ${ }^{137}$ Collaboration studies evaluated interprofessional teams and shared-care models for overall care, transition to homecare, fall prevention, formal and informal caregiver communication, and cooperation between device manufacturers and health care teams. ${ }^{138-143}$ In terms of identification/evaluation as a means of improving care, two studies focused on the Preferred Reporting Items for Systematic Reviews and Meta-Analyses and Omaha Systems. ${ }^{144,145}$ Specific tools evaluated included the Resident Assessment Instrument - Homecare. ${ }^{146-150}$ Other tools evaluated were the Support Needs Assessment, the FiveRepetition Sit-to-Stand Test, the Care Dependency Scale, and the Palliative Prognostic Index. ${ }^{146,151-153}$

\section{What is the scope of technology and the future direction of homecare delivery?}

Information and communications technology (ICT) is making significant strides toward improving the delivery of homecare. It is difficult to envisage the future of homecare without ICT playing a significant role. There are a variety of ICT tools that can increase accessibility to homecare and enable people to gain control of their illness and promote self-management. ${ }^{154}$ However, surprisingly few studies (28) focused specifically on telehealth, telemonitoring, and other technological interventions within the context of patient and carer needs. There were of course many more studies on the technical development and implementation of such tools, but they are beyond the scope of this study.

Four of these studies detailed successful outcomes of trialing telehealth support for medication and related symptoms, including a shared electronic care plan for professionals. $^{35,155-158}$ Seven studies reported successful outcomes of telemonitoring. ${ }^{106,159-164}$ Mobile computing devices for information sharing, decision making, communication, and developing social capital were developed. ${ }^{165-171}$ Technologically supported systems for self-management and home-therapy techniques were also reported. ${ }^{171,172}$ Practitioner caution on the use of mobile technology was explored, and the need for educational resources and user-centered design in implementing technological solutions was identified. ${ }^{146,173}$ The important role that assistive devices play for homecare staff (time and cooperation) and patients (coping and emotion) was assessed. ${ }^{174}$ Devices reported on were a self-administrative device for subcutaneous immunoglobulin therapy, continuous drug delivery through an infusion set versus pump, a mobile ultrasound device, and a lightweight hospital bed for use in the home (easy to assemble and transport). ${ }^{69,175,176}$

Usability and cost models for medication dispensers and safety in homecare were assessed. ${ }^{88,177}$ The development of mobile clinical pathology laboratories for homecare was looked at, where equivalence of mobile and clinical laboratory measurements was achieved. ${ }^{178}$ These add value by assuring provision of laboratory results for homecare patients in minutes, allowing real-time modifications in therapy and reducing the number of second visits by a homecare team. While mobile laboratory tests were more expensive, this was offset against savings in patient hospitalization and reduced second visits.

Simulations offer promising solutions for improved training to enable professionals to manage the complex homecare environment. For example, a human patient simulation has recently been developed for education of homecare nurses. The program enables studies to increase nurses' confidence in dealing with the homecare environment. ${ }^{179} \mathrm{~A}$ similar

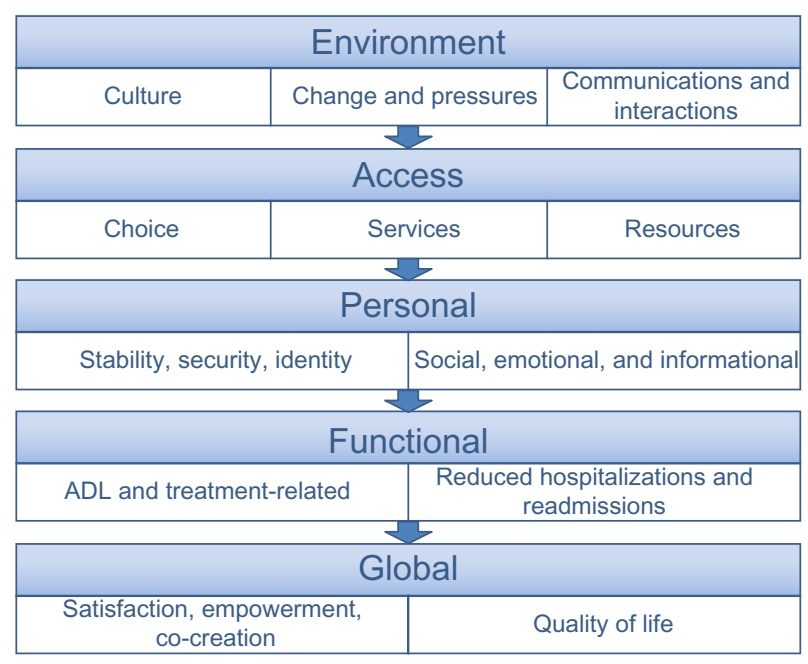

Figure I A framework to understand stakeholder homecare needs. Abbreviation: ADL, activities of daily living. 
simulation technology was used for teaching medication management for homecare nurses, with a significant increase in nurse self-confidence and improved knowledge of medication management. ${ }^{180}$ A particular advantage of this approach was that students made mistakes in the simulations, which they may have made in the real setting. Others are exploring the use of virtual reality for homecare training, eg, the Living Environments Lab (Wisconsin Institute for Discovery, Madison, WI, USA), a fully-immersive six-sided virtual reality computer-assisted virtual environment to enable recreation of household environments. ${ }^{181}$

\section{Conclusion}

The future of homecare is promising, with exciting developments in technology to help us optimize systems, realize the full benefits of care, identify best practices, and help us to meet the oncoming challenges of an ever-aging population in place. The home as a therapeutic setting enables elders to age in place and facilitates patient empowerment, self-care, and QoL. It is envisaged that self-management of health will become more of the norm than the exception in the future, complicated and driven by the aging population. ${ }^{13}$ In this regard, homecare can be an efficient mode of service delivery, although this is by no means conclusive.

The scope of the studies on homecare needs reviewed here is vast and varied. Research is understandably fragmented, both by topic (many studies adopt a narrow focus) and geographically (there is a paucity of comparative studies by country or culture). Despite calls for more integrated studies, ${ }^{6}$ these are still lacking. Given that the needs of patients and both formal and informal carers are complex, to take our understanding of needs forward will require building on the emerging stream of research conceptualizing the home as a caring environment. While it is challenging to answer calls for a uniform framework of patient and carer needs to advance homecare research, it is also necessary. Figure 1 presents a framework that draws together the needs identified within this review.

Patient and caregiver (formal and informal) needs can be categorized at multiple, interdependent levels. We can locate studies within this matrix to understand their meaning within the broader categories of needs. More importantly, we can use such a framework to guide a more holistic approach both to incorporate multiple needs categories within our studies and to illustrate how significant technological developments apply to and fulfill these needs. The latter point is strongly indicated by the lack of studies that transparently link needs and technology.
Finally, three key areas are identified to drive future research agendas. Firstly, the cultural context and social drivers of care-seeking and care-giving behaviors need to be understood in terms of how these differentially impact on care provision and acceptance. ${ }^{74}$ Within this, the ethical implications of the shift from institutional care to technologyassisted homecare and the subsequent impact on the care recipient and formal and informal care providers should be evaluated. ${ }^{15}$ On one level, we could explore in more depth the differences between rural and remote communities in terms of cultural and support networks and the impact on care provision. On another level, we should encourage more international comparative studies to help to understand the contrasting impact of diverse cultures and environments (eg, Japan, Scandinavia, and the US).

Secondly, homecare takes place in a complex environment, with multiple stakeholders. The need for information sharing and collaboration between stakeholders is essential to optimize outcomes for patients, their families, and professionals. However, this is the area of most controversy and concern; we do not yet know how best to achieve stakeholder collaboration. Increasingly, studies are focusing on the development of new care models that can foster successful collaborations. A future research agenda that focuses on the use of informatics for information sharing is indicated. ${ }^{21} \mathrm{An}$ unusual program to educate a local community on the use of opioids with the goal of building capital in the community for future care is noteworthy. ${ }^{182}$

Thirdly, it is clear that technology has a crucial role to play in enabling us to optimize the advantages of homecare: 1) technology changes the nature of homes in the future, eg, assistive and monitoring devices, 2) brings formal services closer to the home, eg, mobile laboratories, 3) serves a vital function in communication, eg, multistakeholder collaboration, and 4) greatly expands the scope of training, eg, simulated environments. As part of a plan of integrated studies, technology must be developed and assessed in relation to specific stakeholder needs rather than as part of fragmented pilot projects.

\section{Disclosure}

The author reports no conflicts of interest in this work.

\section{References}

1. Leff B, Burton J. The future history of home care and physician house calls in the United States. J Gerontol A Biol Sci Med Sci. 2001;56(10): M603-M608.

2. Williams A. Changing geographies of care: employing the concept of therapeutic landscapes as a framework in examining home space. Soc Sci Med. 2002;55(1):141-154. 
3. Shepperd S, Iliffe S. Hospital at home versus in-patient hospital care. Cochrane Database Syst Rev. 2005;(3):CD000356.

4. Genet N, Kroneman M, Boerma WG. Explaining governmental involvement in home care across Europe: an international comparative study. Health Policy. 2013;110(1):84-93.

5. Boling PA, Chandekar RV, Hungate B, Purvis R, Selby-Penczak R, Abbey LJ. Improving outcomes and lowering costs by applying advanced models of in-home care. Cleve Clin J Med. 2013;80 Electronic Suppl 1:eS7-eS14.

6. Genet N, Boerma WG, Kringos DS, et al. Home care in Europe: a systematic literature review. BMC Health Serv Res. 2011;11:207.

7. Jack BA, Baldry CR, Groves KE, Whelan A, Sephton J, Gaunt K. Supporting home care for the dying: an evaluation of healthcare professionals' perspectives of an individually tailored hospice at home service. J Clin Nurs. 2013;22(19-20):2778-2786.

8. Terry M. Evidence-based practices in home care: how are we doing? Home Healthc Nurse. 2012;30(10):615-616.

9. Rigby M, Hill P, Koch S, Keeling DI. Social care informatics as an essential part of holistic health care: a call for action. Int J Med Inform. 2011;80(8):544-554.

10. Hautsalo K, Rantanen A, Astedt-Kurki P. Family functioning, health and social support assessed by aged home care clients and their family members. J Clin Nurs. 2013;22(19-20):2953-2963.

11. Turjamaa R, Hartikainen S, Pietilä AM. Forgotten resources of older home care clients: focus group study in Finland. Nurse Health Sci. 2013;15(3):333-339.

12. Cheung WY, Barmala N, Zarinehbaf S, Rodin G, Le LW, Zimmermann C. The association of physical and psychological symptom burden with time to death among palliative cancer outpatients. J Pain Symptom Manage. 2009;37(3):297-304.

13. Marrelli T, Narayan MC. Self-care, health models, and an International Home Care Nurses Organization update. Home Healthc Nurse. 2013;31(9):457-459.

14. Relph E. Senses of place and emerging social and environmental challenges. In: Eyles J, Williams J. Sense of Place, Health and Quality of Life. Aldershot, UK: Ashgate; 2008:31-44.

15. England K, Dyck I. Managing the body work of home care. Sociol Health Illn. 2011;33(2):206-219.

16. Eloranta S, Arve S, Isoaho H, Welch A, Viitanen M, Routasalo P. Perceptions of the psychological well-being and care of older home care clients: clients and their carers. J Clin Nurs. 2010;19(5-6):847-855.

17. Bucaj A, Kalokerinou A, Sourtzi P. [Considerations on home care in Greece, Italy and Albania: similarities and differences]. Prof Inferm. 2012;65(2):81-88. Italian

18. Thumé E, Facchini LA, Wyshak G, Campbell P. The utilization of home care by the elderly in Brazil's primary health care system. Am J Public Health. 2011;101(5):868-874.

19. Borowiak E, Kostka T. Comparative characteristics of the home care nursing services used by community-dwelling older people from urban and rural environments. $J A d v$ Nurs. 2013;69(6):1259-1268.

20. Lavoie JG, Gervais L. Access to primary health care in rural and remote aboriginal communities: progress, challenges, and policy directions. In: Kulig JC, Williams AM, editors. Health in Rural Canada. Vancouver: University of British Columbia Press; 2011

21. Kitchen P, Williams A, Pong RW, Wilson D. Socio-spatial patterns of home care use in Ontario, Canada: a case study. Health Place. 2011; 17(1):195-206.

22. Demaerschalk MF, Vanden Boer LE, Bronselaer JL, Molenberghs G, Declercq AG. The influence of municipal characteristics on the use of informal home care and home care services by the elderly Flemish. Eur J Public Health. 2013;23(2):241-246.

23. Kieswetter E, Polhhausen S, Uhlig K, et al. Malnutrition is related to functions impairment in older adults receiving home care. J Nutr Health Aging. 2013;17(4):345-350.

24. Thayyil J, Cherumanalil JM. Assessment of status of patients receiving palliative home care and services provided in a rural area - Kerala, India. Indian J Palliat Care. 2012;18(30):213-218.
25. Robison J, Shugrue N, Porter M, Fortinsky RH, Curry LA. Transition from home care to nursing home: unmet needs in a home- and community-based program for older adults. J Aging Soc Policy. 2012;24(3):251-270.

26. Foebel AD, Heckman GA, Hirdes JP, et al. Clinical, demographic and functional characteristics associated with pharmacotherapy for heart failure in older home care clients: a retrospective, population-level, cross-sectional study. Drugs Aging. 2011;28(7):561-573.

27. Mittman N, Isogai PK, Saskin R, et al. Population-based home care services in breast cancer: utilization and costs. Curr Oncol. 2012;19(6): e383-e391.

28. Jang RW, Burman D, Swami N, et al. Impact of an oncology palliative care clinic on access to home care services. Am J Hosp Palliat Care. 2013;30(5):425-431.

29. Nanda A, Bourbonniere M, Wetle T, Teno J. Home care in the last year of life: family member perceptions of unmet need associated with last place of care. J Am Med Dir Assoc. 2010;11(1):21-25.

30. Li H, Kyrouac GA, McManus DQ, Cranston RE, Hughes S. Unmet home care service needs of rural older adults with Alzheimer's disease: a perspective of informal caregivers. J Gerontol Soc Work. 2012;55(5):409-425.

31. Berland A, Holm AL, Gundersen D, Bentsen SB. Patient safety culture in home care: experiences of home-care nurses. J Nurs Manag. 2012;20(6):794-801.

32. Ayalon L, Fialová D, Areán PA, Onder G. Challenges associated with recognition and treatment of depression in older recipients of home care services. Int Psychogeriatr. 2010;22(4):514-522.

33. Li LW, Conwell Y. Pain and self-injury ideation in elderly men and women receiving home care. J Am Geriatr SocJ Am Geriatr Soc. 2010;58(11):2160-2165.

34. Yoo IY. [Analysis of multi-variate recurrent fall risk factors in elderly people using Residential Assessment Instrument - Home Care: comparisons between single and recurrent fallers. J Korean Acad Nurs. 2011;41(1):119-128. Korean.

35. Meijers JM, Halfens RJ, Neyens JC, Luiking YC, Verlaan G, Schols JM. Predicting falls in elderly receiving home care: the role of malnutrition and impaired mobility. J Nutr Health Aging. 2012;16(7): 654-658.

36. Willumsen T, Fjaera B, Eide H. Oral health-related quality of life in patients receiving home-care nursing: associations with aspects of dental status and xerostomia. Gerodontology. 2010;27(4):251-257.

37. Stolt M, Suhonen R, Voutilainen P, Leino-Kilpi H. Foot health in older people and the nurses' role in foot health care - a review of literature. Scand J Caring Sci. 2010;24(1):194-201.

38. Furuta M, Komiya-Nonaka M, Akifusa S, et al. Interrelationship of oral health status, swallowing function, nutritional status and cognitive ability with activities of daily living in Japanese elderly people receiving home care services due to physical disabilities. Community Dent Oral Epidemiol. 2013;41(2):173-181.

39. Iizaka S, Okuwa M, Sugama J, Sanada H. The impact of malnutrition and nutrition-related factors on the development and severity of pressure ulcers in older patients receiving home care. Clin Nutr. 2010;29(1):47-53.

40. Dierich MT, Mueller C, Westra BL. Medication regimens in older home care patients. J Gerontol Nurs. 2011;37(12):45-55.

41. Sears N, Baker GR, Barnsley J, Shortt S. The incidence of adverse events among home care patients. Int J Qual Health Care. 2013;25(1): $16-28$.

42. Caciula I, Livingston G, Caiula R, Cooper C. Recognition of elder abuse by home care workers and older people in Romania. Int Psychogeriatr. 2010;22(3):403-408.

43. Sancho A, Albiol R, Mach N. [Relationship between nutritional status and the risk of having pressure ulcers in patients included in a home care program]. Aten Primaria. 2012;44(10):586-594. Spanish.

44. Sørbye LW. Cancer in home care: unintended weight loss and ethical challenges. A cross-sectional study of older people at 11 sites in Europe. Arch Gerontol Geriatr. 2011;53(1):64-69. 
45. Landi F, Liperoti R, Lattanzio F, et al. Effects of anorexia on mortality among older adults receiving home care: an observational study. J Nutr Health Aging. 2012;16(1):79-83.

46. Tsai YC, Lin SY, Liu Y, Wang RH. Factors related to the development of pressure ulcers among new recipients of home care services in Taiwan: a questionnaire study. Int J Nurs Stud. 2012;49(11): 1383-1390.

47. Meyer-Massetti C, Kaiser E, Hedinger-Grogg B, Luterbacher S, Hersberger K. [Medication safety in the home care setting: error-prone process steps]. Pflege. 2012;25(4):261-269. German.

48. Vink J, Morton D, Ferreri S. Pharmacist identification of medicationrelated problems in the home care setting. Consult Pharm. 2011;26(7): 477-484.

49. Lux EA, Heine J. [Home care treatment of cancer pain patients with patient-controlled analgesia (PCA)]. Schmerz. 2011;25(6):663-667. German.

50. Mercadante S, Porzio G, Valle A, Fusco F, Aielli F, Costanzo V. Palliative sedation in patients with advanced cancer followed at home: a systematic review. J Pain Symptom Manage. 2011;41(4):754-760.

51. Doran DM, Hirdes JP, Blais R, et al. Adverse events among Ontario home care clients associated with emergency room visit or hospitalization: a retrospective cohort study. BMC Health Serv Res. 2013;13:227.

52. Markle-Reid M, Browne G, Gafni A, et al. A cross-sectional study of the prevalence, correlates, and costs of falls in older home care clients 'at risk' for falling. Can J Aging. 2010;29(1):119-137.

53. Leclerc BS, Bégin C, Cadieux E, et al. Relationship between home hazards and falling among community-dwelling seniors using homecare services. Rev Epidemiol Sante Publique. 2010;58(1):3-11.

54. Grue EV, Finne-Soveri H, Stolee P, et al. Recent visual decline - a health hazard with consequences for social life: a study of home care clients in 12 countries. Curr Gerontol Geriatr Res. Epub August 4, 2010.

55. Bohannon RW. Grip strength impairments among older adults receiving physical therapy in a home-care setting. Percept Mot Skills. 2010; 111(3):761-764.

56. Ayalon L, Halevy-Levin S, Ben-Yizhak Z, Friedman G. Family caregiving at the intersection of private care by migrant home care workers and public care by nursing staff. Int Psychogeriatr. 2013;25(9):1463-1473.

57. Szczerbińska K, Hirdes JP, Zyczkowska J. Good news and bad news: depressive symptoms decline and undertreatment increases with age in home care and institutional settings. Am J Geriatr Psychiatry. 2012;20(12):1045-1056

58. Pérodeau G, Paradis I, Grenier S, O’Connor K, Grenon E. Chronic psychotropic drug use among frail elderly women receiving home care services. J Women Aging. 2011;23(4):321-341.

59. Turpin LJ, McWilliam CL, Ward-Griffin C. The meaning of a positive client-nurse relationship for senior home care clients with chronic disease. Can J Aging. 2012;31(4):457-469.

60. Ayalon L, Shiovitz-Ezra S, Palgi Y. No place like home? Potential pathways to loneliness in older adults under the care of a live-in foreign home care worker. J Psychol. 2012;46(1-2):189-200.

61. Bergkvist K, Larsen J, Johansson UB, Mattsson J, Svahn BM. Hospital care or home care after allogeneic hematopoietic stem cell transplantation - patients' experiences of care and support. Eur J Oncol Nurs. 2013;17(4):389-395.

62. Swedberg L, Chiriac EH, Törnkvist L, Hylander I. Patients in 24-hour home care striving for control and safety. BMC Nurs. 2012;11:9.

63. Kodama Y, Matsumura T, Yamaguchi T, et al. Age, gender, will, and use of home-visit nursing care are critical factors in home care for malignant diseases; a retrospective study involving 346 patients in Japan. BMC Palliat Care. 2011;10:17.

64. Vermandere M, De Lepeleire J, van Mechelen W, Warmenhoven F, Thoonsen B, Aertgeerts B. Outcome measures of spiritual care in palliative home care: a qualitative study. Am J Hosp Palliat Care. 2013;30(5):437-444.
65. Olsson L, Ostlund G, Strang P, Grassman E, Friedrichsen M. The glimmering embers: experiences of hope among cancer patients in palliative home care. Palliat Support Care. 2011;9(1):43-54.

66. Romagnoli KM, Handler SM, Ligons FM, Hochheiser H. Home-care nurses' perceptions of unmet information needs and communication difficulties of older patients in the immediate post-hospital discharge period. BMJ Qual Saf. 2013;22(4):324-332.

67. Vyhnalek B, Heilmeier B, Borasio GD. [Specialized palliative home care (SAPV) in an urban setting - a first year experience]. $M M W$ Fortschr Med. 2011;153 Suppl 2:41-46. German.

68. Westra BL, Bliss DZ, Savik K, Hou Y, Borchert A. Effectiveness of wound, ostomy, and continence nurses on agency-level wound and incontinence outcomes in home care. $J$ Wound Ostomy Continence Nurs. 2013;40(1):25-53.

69. Silva Júnior AJ, Posso MB, de Vasconcellos N, Laurentino C. [Hospital bed project for home care]. Rev Esc Enferm USP. 2010;44(20):302-307. Portuguese.

70. Espinel-Bermúdez MC, Sánchez-García S, Juárez-Cedillo T, García-González JJ, Viveros-Pérez Á, García-Peña C. [Impact of the program Home Care for the Chronically Ill for elderly: quality of life and hospital readmissions]. Salud Publica Mex. 2011; 53(1):17-25.

71. King AI, Parsons M, Robinson E, Jorgensen D. Assessing the impact of a restorative home care service in New Zealand: a cluster randomized controlled trial. Health Soc Care Community. 2012;20(4):365-374.

72. Tralongo $P$, Ferraù $F$, Borsellino $N$, et al. Cancer patient-centered home care: a new model for health care in oncology. Ther Clin Risk Manag. 2011;7:387-392

73. Markle-Reid M, Browne G, Gafni A. Nurse-led health promotion interventions improve quality of life in frail older home care clients: lessons learned from three randomized trials in Ontario, Canada. J Eval Clin Pract. 2013;19(1):118-131.

74. Donovan R, Williams A, Stajduhar K, Brazil K, Marshall D. The influence of culture on home-based family caregiving at end-of-life: a case study of Dutch reformed family care givers in Ontario, Canada. Soc Sci Med. 2011;72(3):338-346.

75. Wilde A, Glenginning C. 'If they're helping me then how can I be independent?' The perceptions and experience of users of home-care re-ablement services. Health Soc Care Community. 2012;20(6): 583-590.

76. Rabiee P, Glendenning C. Organisation and delivery of home care re-ablement: what makes a difference? Health Soc Care Community. 2011;19(5):495-503.

77. Lewin G, Vandermeulen S. A non-randomized controlled trial of the Home Independence Program (HIP): an Australian restorative programme for older home-care clients. Health Soc Care Community. 2010;18(1):91-99.

78. Parsons JG, Sheridan N, Rouse P, Robinson E, Connolly M. A randomized controlled trial to determine the effect of a model of restorative home care on physical functions and social support among older people. Arch Phys Med Rehabil. 2013;94(6):1015-1022.

79. Burton E, Lewin G, Boldy D. Physical activity levels of older adults receiving a home care service. J Aging Phys Act. 2013;21(2): 140-154.

80. Tinetti ME, Charpentier P, Gottschalk M, Baker DI. Effect of a restorative model of posthospital home care on hospital readmissions. $J \mathrm{Am}$ Geriatr Soc. 2012;60(8):1521-1526.

81. Marek KD, Stetzer F, Adams SJ, Popejoy LL, Rantz M. Aging in place versus nursing home care: comparison of costs to Medicare and Medicaid. Res Gerontol Nurs. 2012;5(2):123-129.

82. Tanaka Y, Fukui M, Nakamura F, et al. [A cross-sectional study of the current status of respiratory home care patients and their caregivers in Osaka Prefecture]. Nihon Kokyuki Gakkai Zasshi. 2011;49(8):559-568. Japanese.

83. Tomoko N, Eriko A, Hisataka S. Social support associated with quality of life in home care patients with intractable neurological disease in Japan. Nurs Res Pract. 2012;2012:402032. 
84. Ceci C, Purkis ME, Björnsdóttir K. Theorizing accommodation in supportive home care for older people. J Aging Stud. 2013;27(1): 30-37.

85. Lüthi F, Fucina N, Divorne N, et al. Home care - a safe and attractive alternative to inpatient administration of intensive chemotherapies. Support Care Cancer. 2012;20(3):575-581.

86. Hekkert KD, Cihangir S, Kleefstra SM, van den Berg B, Kool RB. Patient satisfaction revisited: a multilevel approach. Soc Sci Med. 2009;69(1):68-75.

87. Levine C, Halper D, Peist A, Gould DA. Bridging troubled waters: family caregivers, transitions, and long-term care. Health Affairs. 2010;29(1):116-124

88. Reeder B, Demiris G, Marek KD. Older adults' satisfaction with a medication dispensing device in home care. Inform Health Soc Care. 2013;38(3):211-222.

89. Lednik L, Baket M, Sullivan K, Poynter M, O’Quinn L, Smith C. Is self-administration of subcutaneous immunoglobulin therapy safe in a home care setting? Home Healthc Nurse. 2013;31(3):134-141.

90. Broadhurst $D$. Transition to an elastomeric infusion pump in home care: an evidence-based approach. J Infus Nurs. 2012;35(3):143-151.

91. Mpinga EK, Chastonay P. Satisfaction of patients: a right to health indicator? Health Policy. 2011;10(2):144-150.

92. Firbank OE. Connecting the voices of users, caregivers and providers on service quality: a study of home-care services. Int $J$ Health Care Qual Assur. 2012;25(5):403-420.

93. Aletras VH, Kostarelis A, Tsitouridou M, Niakas D, Nicolaou A. Development and preliminary validation of a questionnaire to measure satisfaction with home care in Greece: an exploratory factor analysis of polychoric correlations. BMC Health Serv Res. 2010;10:189.

94. Byrne K, Sims-Gould J, Frazee K, Martin-Matthews A. "I'm satisfied ... but": clients' and families' contingent responses about home care. Home Health Care Serv Q. 2011;30(4):161-177.

95. Bikker AP, Thompson AG. Predicting and comparing patient satisfaction in four different modes of health care across a nation. Soc Sci Med. 2006;63(6):1671-1683.

96. Jiménez S, Aguilò A, Gil V, et al. [Psychosocial factors determine patients' acceptance of emergency department discharge directly to hospital-at-home care]. Gac Sanit. 2010;24(4):303-308. Spanish.

97. Chen G, Khan N, King KM, Hemmelgarn DR, Quan H. Home care utilization and outcomes among Asian and other Canadian patients with heart failure. BMC Cardiovasc Disord. 2010;10:12.

98. Rahme E, Kahn S, Dasgupta K, et al. Short-term mortality associated with failure to receive home care after hemiarthroplasty. CMAJ. 2010;182(13):142-146.

99. Naomi A, Shiroiwa T, Fukuda T, Murahima S. Institutional care versus home care for the elderly in a rural area: cost comparison in rural Japan. Rural Remote Health. 2012;12:1817.

100. Seow H, Barbera L, Howell D, Dy SM. How end-of-life home care services are used from admission to death: a population-based cohort study. J Palliat Care. 2010;26(4):270-278.

101. Mollaoğlu M, Kayataş M, Yürügen B. Effects on caregiver burden of education related to home care in patients undergoing hemodialysis. Hemodial Int. 2013;17(3):413-420.

102. Ishii Y, Miyashita M, Sato K, Ozawa T. Family's difficulty scale in end-of-life home care: a new measure of the family's difficulties in caring for patients with cancer at the end of life at home from bereaved family's perspective. J Palliat Med. 2012;15(2):210-215.

103. Hirdes JP, Freeman S, Smith TR, Stolee P. Predictors of caregiver distress among palliative home care clients in Ontario: evidence based on the interRAI Palliative Care. Palliat Support Care. 2012;10(3):155-163.

104. Townsend AL, Ishler KJ, Shapiro BM, Ford Pitorak E, Matthews CR. Levels, types, and predictors of family caregiver strain during hospice home care for an older adult. $J$ Soc Work End Life Palliat Care. 2010;6(1-2):51-72.

105. Smith CE, Piamjariyakul U, Yadrich DM, Ross VM, Gajewski B, Williams AR. Complex home care: part III - economic impact on family caregiver quality of life and patients' clinical outcomes. Nurs Econ. 2010;28(6):393-399, 414.
106. McKenzie B, Bowen ME, Keys K, Bulat T. Safe home program: a suite of technologies to support extended home care of persons with dementia. Am J Alzheimers Dis Other Demen. 2013;28(4): 348-354.

107. Buscher A, Astedt-Kurki P, Paavilainen E, Schepp W. Negotiations about helpfulness - the relationship between formal and informal care in home care arrangements. Scand J Caring Sci. 2011;25(4): 706-715.

108. Oliveira AR, Rodrigues RC, de Sousa VE, Costa AG, Lopes MV, de Araujo TL. Clinical indicators of 'caregiver role strain' in caregivers of stroke patients. Contemp Nurse. 2013;44(2):215-224.

109. Linderholm M, Friedrichsen M. A desire to be seen: family caregivers' experiences of their caring role in palliative home care. Cancer Nurs. 2010;33(1):28-36.

110. Stajduhar KI, Funk L, Outcalt L. Family caregiver learning - how family caregivers learn to provide care at the end of life: a qualitative secondary analysis of four datasets. Palliat Med. 2013;27(7):657-664.

111. Eriksson H, Sandberg J, Hellström I. Experiences of long-term home care as an informal caregiver to a spouse: gendered meanings in everyday life for female carers. Int J Older People Nurs. 2013;8(2):159-165.

112. Craven C, Byrne K, Sims-Gould J, Martin-Matthews A. Types and patterns of safety concerns in home care: staff perspectives. Int J Qual Health Care. 2012;24(5):525-531.

113. Larsson A, Karlqvist L, Westerberg M, Gard G. Identifying work ability promoting factors for home care aides and assistant nurses. $B M C$ Musculoskelet Disord. 2012;13:1.

114. Doniol-Shaw G, Lada E. Work schedules of home care workers for the elderly in France: fragmented work, deteriorating quality of care, detrimental health impact. Work. 2011;40 Suppl 1:S31-S46.

115. Ward-Griffin C, McWillliam C, Oudhoorn A. Negotiating relational practice patterns in palliative home care. J Palliat Care. 201;28(2):97-104.

116. Vik K, Eide AH. The exhausting dilemmas faced by home-care service providers when enhancing participation among older adults receiving home care. Scand J Caring Sci. 2012;26(3):528-536.

117. Moorman SM, Macdonald C. Medically complex home care and caregiver strain. Gerontologist. 2013;53(3):407-417.

118. de Figueiredo RM, Maroldi MAC. Home care: health professionals at risk for biological exposure. Rev Esc Enferm USP. 2012;46(1): 146-150.

119. Amuwo S, Sokas RK, McPahaul K, Lipscomb J. Occupational risk factors for blood and body fluid exposure among home care aides. Home Health Care Serv Q. 2011;30(2):96-114.

120. Leiss JK, Sitzman KL, Kendra MA. Provision and use of personal protective equipment among home care and hospice nurses in North Carolina. Am J Infect Control. 2011;39(2):123-128.

121. Spegel H, Höller C, Randzio O, Liebl B, Herr C. [Infection control management and practice in home care - analysis of structure quality]. Gesundheitswesen. 2013;75(2):111-118. German.

122. de Almeida Freitas IB, Meneghel SN, Selli L. [The construction of care by the health team and the caretaker within a home-care program for bedridden patients in Porto Algere (RS, Brazil)]. Ciencia Saude Colect. 2010;16(1):301-310. Portuguese.

123. Devlin M, McIlfatrick S. Providing palliative and end-of-life care in the community: the role of the home-care worker. Int J Palliat Nurs. 2010;16(4):195-203.

124. Funk LM, Stajduhar KI, Purkis ME. An exploration of empowerment discourse within home-care nurses' accounts of practice. Nurs Inq. 2011;18(1):66-76.

125. Hirano Y, Yamamoto-Mitani N, Ueno M, et al. Home care nurses' provision of support to families of the elderly at the end of life. Qual Health Res. 2011;21(2):199-213.

126. Delaney C, Apostolidis B, Lachapelle L, Fortinsky R. Home care nurses' knowledge of evidence-based education topics for management of heart failure. Heart Lung. 2011;40(4):285-292.

127. Lindahl B, Lidèn E, Lindblad BM. A meta-synthesis describing the relationships between patients, informal caregivers and health professionals in home-care settings. J Clin Nurs. 2011;20(3-4):454-463. 
128. Li LW, McLaughlin SJ. Caregiver confidence: does it predict changes in disability among elderly home care recipients? Gerontologist. 2012;52(1):79-88.

129. Brogaard T, Jensen AB, Sokolowski I, Olesen F, Neergaard MA. Who is the key worker in palliative home care? Scand J Prim Health Care. 2011;29(3):150-156.

130. Neergaard MA, Olesen F, Jensen AB, Sondergaard J. Shared care in basic level palliative home care: organizational and interpersonal challenges. J Palliat Med. 2010;13(9):1071-1077.

131. Stolee P, Steeves B, Manderson BL, Toscan J L, Glenny C, Berg K. Health information use in home care: brainstorming barriers, facilitators, and recommendations. Home Health Care Serv $Q$. 2010;29(1):37-53.

132. Winge M, Johansson LA, Nyström M, Lindh-Waterworth E, Wangler B. Need for a new care model - getting to grips with collaborative home care. Stud Health Technol Inform. 2010;160(Pt 1):8-12.

133. Wollscheid S, Eriksen J, Hallvik J. Undermining the rules in home care services for the elderly in Norway: flexibility and cooperation. Scand J Caring Sci. 2013;27(2):414-421.

134. Eloranta S, Arve S, Isoaho H, Routasalo P. Home care from the perspective of older clients and their professional carers. Arch Gerontol Geriatr. 2010;51(2):180-184.

135. van den Bussche H, Jahncke-Latteck AD, Ernst A, Tetzlaff B, Wiese B, Schramm U. [Satisfied general practitioners and critical nursing staffproblems of interprofessional cooperation in the home care of dementia patients]. Gesundheitswesen. 2013;75(5):328-333. German.

136. Reidt S, Morgan J, Larson T, Blade MA. The role of a pharmacist on the home care team: a collaborative model between a college of pharmacy and a visiting nurse agency. Home Healthc Nurse. 2013;31(2): 80-87.

137. Pype P, Symons L, Wens J, et al. Healthcare professionals' perceptions toward interprofessional collaboration in palliative home care: a view from Belgium. J Interprof Care. 2013;27(4):313-319.

138. Butler SS, Wardamsky S, Brennan-Ing M. Older women caring for older women: the rewards and challenges of the home care aide job. J Women Aging. 2012;24(3):194-215.

139. Howell D, Marshall D, Brazil K, et al. A shared care model pilot for palliative home care in a rural area: impact on symptoms, distress and pace of death. J Pain Symptom Manage. 2011;42(1):60-75.

140. Kelly MM, Penney ED. Collaboration of hospital case managers and home care liaisons when transitioning patients. Prof Case Manag. 2011;16(3):128-136.

141. Markle-Reid M, Browne G, Amiram R, et al. The effects and costs of a multifactorial and interdisciplinary team approach to falls prevention for older home care clients 'at risk' for falling: a randomized controlled trial. Can J Aging. 2010;29(1):139-161.

142. Bossen C, Christensen LR, Grönvall E, Vestergaard LS. CareCoor: Augmenting the coordination of cooperative home care work. Int $J$ Med Inform. 2013;82(5):e189-e199.

143. Baumgarten K, Hale Y, Messonnier M, McCabe M, Albright M, Bergeron E. Bridging the gap: a collaborative to reduce peripherally inserted central catheter infections in the home care environment. Ochsner J. 2013;13(3):352-358.

144. Dubuc N, Dubois MF, Raîche M, Gueye NR, Hébert R. Meeting the home-care needs of disabled older persons living in the community: does integrated services delivery make a difference? BMC Geriatr. 2011;11:67.

145. Westra BL, Oancea C, Savik K, Marek KD. The feasibility of integrating the Omaha system data across home care agencies and vendors. Comput Inform Nurs. 2010;28(3):162-171.

146. Parsons M, Senior H, Mei-Hu Chen X, et al. Assessment without action; a randomised evaluation of the interRAI home care compared to a national assessment tool on identification of needs and service provision for older people in New Zealand. Health Soc Care Community. 2013;21(5):536-544.

147. Cook RJ, Berg K, Lee KA, Poss JW, Hirdes JP, Stolee P. Rehabilitation in home care is associated with functional improvement and preferred discharge. Arch Phys Med Rehabil. 2013;94(6):1038-1047.
148. Burla L, Schaffert R, Mylaeus M, Rüesch P. [Developing and testing quality indicators of home care in Switzerland]. Gesundheitswesen. 2010;72(2):106-113. German.

149. Monod S, Hongler T, Castelli T, Clivaz-Luchez P, Büla C. [The Resident Assessment Instrument Home care: what primary care physician needs to know]. Rev Med Suisse. 2011;7(316):2176, 2178-2183. French.

150. Leung DY, Leung AY, Chi I. An evaluation of the factor structure of the Instrumental Activities of Daily Living Involvement and Capacity scales of the minimum data set for home care for elderly Chinese community dwellers in Hong Kong. Home Health Care Serv $Q$. 2011;30(3):147-159

151. Bohannon RW. Five-repetition sit-to-stand test: usefulness for older patients in a home-care setting. Percept Mot Skills. 2011;112(3):803-806.

152. Kottner J, Halfens R, Dassen T. Interrater reliability and agreement of the Care Dependency Scale in the home care setting in The Netherlands. Scand J Caring Sci. 2010;24 Suppl 1:56-61.

153. Hamano J, Maeno T, Kizawa Y, Shima Y, Maeno T. Usefulness of Palliative Prognostic Index for patient with advanced cancer in home care setting. Am J Hosp Palliat Care. 2013;30(3):264-267.

154. Lindberg B, Nilsson C, Zotterman D, Söderberg S, Skär L. Using information and communication technology in home care for communication between patients, family members, and healthcare professionals: a systematic review. Int J Telemed Appl. 2013;2013:461829.

155. Craven O, Hughes CA, Burton A, Saunders M, Molassiotis A. Is a nurse-led telephone intervention a viable alternative to nurse-led home care and standard care for patients receiving oral capecitabine? Results from a large prospective audit in patients with colorectal cancer. Eur J Cancer Care (Engl). 2013;22(3):413-419.

156. Bradford N, Armfield NR, Young L, Ehmer M, Smith AC. Safety for home care: the use of internet video calls to double-check interventions. J Telemed Telecare. 2012;18(8):434-437.

157. Ding ST, Wang CL, Huang YH, et al. Demand and predictors for postdischarge medical counseling in home care patients: a prospective cohort study. PloS One. 2013;8(5):e64274.

158. Van de Putte M, Appels S, Boone T, et al. [Role of the community pharmacist in the management of drug related problems in home care patients]. J Pharm Belg. 2012;(3):24-29. French.

159. Browning SV, Clark RC, Poff RM, Todd D. Telehealth monitoring: a smart investment for home care patients with heart failure. Home Healthc Nurse. 2011;29(6):368-374.

160. Martín-Lesende I, Orruño E, Bilbao A, et al. Impact of telemonitoring home care patients with heart failure or chronic lung disease from primary care on healthcare resource use (the TELBIL study randomised controlled trial). BMC Health Serv Res. 2013;13:118.

161. D'Angelo LT, Tarita E, Zywietz TK, Lueth TC. A system for intelligent home care ECG upload and prioritization. Conf Proc IEEE Eng Med Biol Soc. 2010;2010:2188-2191.

162. Hall P, Morris M. Improving heart failure in home care with chronic disease management and telemonitoring. Home Healthc Nurse. 2010;28(10):606-617.

163. Hein A, Winkelbach S, Martens B, et al. Monitoring systems for the support of home care. Inform Health Soc Care. 2010; 35(3-4):157-176.

164. Chen CM. Web-based remote human pulse monitoring system with intelligent data analysis for home health care. Expert Syst Appl. 2011;38(3):2011-2019

165. Pare G, Sicotee C, Moreault MP, Poba-Nzaou P, Nahas G, Templier M. Mobile computing and the quality of home care nursing practice. J Telemed Telecare. 2011;17(6):313-317.

166. Morishima A, Kijima Y. [Sharing patient information using iPads in the introduction of IT for home medical care - construction of a network for home care]. Gan To Kagaku Ryoho. 2010;39 Suppl 1:6-8. Japanese.

167. Doran DM, Reid-Haughian C, Chilcote A, Qing Bai Y. A formative evaluation of nurses' use of electronic devices in a home care setting. Can J Nurs Res. 2013;45(1):54-73. 
168. Johansson PE, Pertersson GI, Nilsson GC. Personal digital assistant with a barcode reader - a medical decision support system for nurses in home care. Int J Med Inform. 2010;79(4):232-242.

169. Tapper L, Quinn H, Kerry J, Brown KG. Introducing handheld computers into home care. Can Nurse. 2012;108(1):28-32.

170. Smith-Stoner M. Webcasting in home and hospice care services: virtual communication in home care. Home Healthc Nurse. 2011;29(6):337-341.

171. Capozzi D, Lanzola G. A configurable home care platform for monitoring patients with reminder messaging and compliance tracking services. Stud Health Technol Inform. 2010; 160(Pt 1):63-67.

172. Varnfield M, Karunanithi MK, Särelä A, et al. Uptake of a technology-assisted home-care cardiac rehabilitation program. Med J Aust. 2011;194(4):S15-S19.

173. Walivaara BM, Andersson S, Axelsson K. General practitioners' reasoning about using mobile distance-spanning technology in home care and in nursing home care. Scand J Caring Sci. 2011;25(1): $117-125$.

174. Or CK, Karsh BT, Severtson DJ, Burke LJ, Brown RL, Brennan PF. Factors affecting home care patients' acceptance of a web-based interactive self-management technology. $\mathrm{J} \mathrm{Am} \mathrm{Med} \mathrm{Inform} \mathrm{Assoc.}$ 2011;18(1):51-59.

175. Mehahem S, Shvartzman P. Continuous subcutaneous delivery of medications for home care palliative patients - using an infusion set or a pump? Support Care Cancer. 2010;18(9):1165-1170.
176. Mariani P, Setla JA. Palliative ultrasound for home care hospice patients. Acad Emerg Med. 2010;17(3):293-296.

177. Macdonald M, Lang A, MacDonald JA. Mapping a research agenda for home care safety: perspectives from researchers, providers, and decision makers. Can J Aging. 2011;30(2):233-245.

178. Facco F, Agazzi A, Manfredini L, Dallorso S, Melioli G. Evaluation of a mobile clinical pathology laboratory developed for the home care of pediatric patients following transplantation of peripheral blood precursor cells. Clin Chem Lab Med. 2013;51(8):1637-1642.

179. Smith SJ, Barry DG. The use of high-fidelity simulation to teach home care nursing. West J Nurs Res. 2013;35(3):297-312.

180. Mager DR, Campbell SH. Home care simulation for student nurses: medication management in the home. Nurse Educ Today. 2013;33(11):1416-1421.

181. Brennan P, Flatley P, Ponto K, Radwin R, Kreutz K. Envisioning the future of home care: applications of immersive virtual reality. Stud Health Technol Inform. 2012;192:599-602.

182. Akai N, Hashimoto D, Fujita T, Miyake K, Hamabe-Fujita W, Tokuyama S. [Proposition and evaluation of the educational activities for effective utilization of opioids performed by pharmacists in palliative home care]. Yakugaku Zasshi. 2010;130(4):605-612. Japanese.
Smart Homecare Technology and TeleHealth

\section{Publish your work in this journal}

Smart Homecare Technology and TeleHealth is an international, peer-reviewed, open access online journal publishing original research, reviews, editorials and commentaries on the application of technology to support people and patients at home and in assisted living centers to optimize healthcare and management resources. Specific topics in the journal include: Development and application of

\section{Dovepress}

devices within the home and embedded in appliances; Healthcare provider com munication and education tools; and drug ordering and adherence. The manuscript management system is completely online and includes a very quick and fair peer-review system, which is all easy to use. Visit http://www.dovepress.com/ testimonials.php to read real quotes from published authors. 